\title{
Shortening of atrioventricular delay at increased atrial paced heart rates improves diastolic filling and functional class in patients with biventricular pacing
}

\author{
Reza Rafie ${ }^{1}$, Salima Qamruddin ${ }^{1}$, Ali Ozhand $^{2}$, Nima Taha ${ }^{1}$ and Tasneem Z Naqvi ${ }^{* *}$
}

\begin{abstract}
Background: Use of rate adaptive atrioventricular (AV) delay remains controversial in patients with biventricular (Biv) pacing. We hypothesized that a shortened AV delay would provide optimal diastolic filling by allowing separation of early and late diastolic filling at increased heart rate (HR) in these patients.

Methods: 34 patients (75 \pm 11 yrs, 24 M, LVEF $34 \pm 12 \%)$ with Biv and atrial pacing had optimal AV delay determined at baseline HR by Doppler echocardiography. Atrial pacing rate was then increased in $10 \mathrm{bpm}$ increments to a maximum of $90 \mathrm{bpm}$. At each atrial pacing HR, optimal AV delay was determined by changing AV delay until best $\mathrm{E}$ and $\mathrm{A}$ wave separation was seen on mitral inflow pulsed wave (PW) Doppler (defined as increased atrial duration from baseline or prior pacemaker setting with minimal atrial truncation). Left ventricular (LV) systolic ejection time and velocity time integral (VTI) at fixed and optimal AV delay was also tested in 13 patients. Rate adaptive AV delay was then programmed according to the optimal AV delay at the highest HR tested and patients were followed for 1 month to assess change in NYHA class and Quality of Life Score as assessed by Minnesota Living with Heart Failure Questionnaire.
\end{abstract}

Results: 81 AV delays were evaluated at different atrial pacing rates. Optimal AV delay decreased as atrial paced HR increased (201 ms at $60 \mathrm{bpm}, 187 \mathrm{~ms}$ at $70 \mathrm{bpm}, 146 \mathrm{~ms}$ at $80 \mathrm{bpm}$ and $123 \mathrm{~ms}$ at $90 \mathrm{bpm}$ (ANOVA F-statistic = $15, p=0.0010)$. Diastolic filling time ( $P<0.001$ vs. fixed AV delay), mitral inflow VTI ( $p<0.05$ vs fixed AV delay) and systolic ejection time ( $p<0.02$ vs. fixed AV delay) improved by $14 \%, 5 \%$ and $4 \%$ respectively at optimal versus fixed AV delay at the same HR. NYHA improved from $2.6 \pm 0.7$ at baseline to $1.7 \pm 0.8(p<0.01) 1$ month post optimization. Physical component of Quality of Life Score improved from $32 \pm 17$ at baseline to $25 \pm 12(p<0.05)$ at follow up.

Conclusions: Increased heart rate by atrial pacing in patients with Biv pacing causes compromise in diastolic filling time which can be improved by AV delay shortening. Aggressive AV delay shortening was required at heart rates in physiologic range to achieve optimal diastolic filling and was associated with an increase in LV ejection time during optimization. Functional class improved at 1 month post optimization using aggressive AV delay shortening algorithm derived from echo-guidance at the time of Biv pacemaker optimization.

Keywords: Biventricular pacemaker, Rate Adaptive AV Delay, Diastolic Function, Echocardiography, Doppler

\footnotetext{
* Correspondence: tnaqvi@usc.edu

'Echocardiographic Laboratories, Department of Medicine, Keck School of Medicine, University of Southern California, Los Angeles, California, 90033 USA

Full list of author information is available at the end of the article
} 
Cardiac resynchronization therapy (CRT) in patients with advanced heart failure leads to an improvement in cardiac function during rest, exercise [1] and pharmacological stress [2]. Previous studies have shown that in patients with CRT, optimizing atrioventricular (AV) delay further improves stroke volume [3-6] and that optimal AV delay changes over time requiring periodic optimization [7]. There is controversy on optimal AV delay at increase in heart rate with exercise. Studies have shown conflicting data suggesting AV delay should be prolonged [8] or shortened $[9,10]$ as heart rate increases. In patients with heart failure, an increase in heart rate can compromise diastolic filling to preserve systolic ejection [11]. This diastolic filling time can be manipulated in heart failure patients with CRT by adjusting AV delay at increased heart rates by using rate adaptive algorithms of CRT devices. In this study in patients with CRT, we evaluated a) the effect of increased atrial pacing rate on diastolic filling at a fixed AV delay and b) to examine the effect of manipulating AV delay on diastolic filling. Our secondary goal was to examine the effect of programming AV delay that provided most optimal diastolic filling at increased heart rate on cardiac ejection acutely and on functional class at 1 month follow up.

\section{Methods}

\section{Study Subjects}

34 heart failure patients with Biv-CRT who were atrially pacing at resting heart rates were included in the study.

\section{Exclusion criteria}

Patients with atrial fibrillation, atrial pacing of less than $50 \%$ on pacemaker interrogation, recent hospital admission within 2 months for congestive heart failure and acute coronary event requiring revascularization within 3 months were excluded from the study. All patients signed an informed consent approved by the Institutional Review Board. 14 patients from this study were part of the 2 studies reported earlier $[5,6]$.

\section{Pacing Protocol}

AV delay and interventricular (VV) delays were optimized at rest using Doppler echocardiography by conventional methods. AV delay that provided that most optimal mitral inflow filling without atrial truncation and with best $\mathrm{E}$ and $\mathrm{A}$ separation was chosen at optimal AV delay. Left ventricular outflow tract (LVOT) pulsed wave (PW) Doppler was measured at rest and at each AV delay along with pulmonary vein PW Doppler. After optimal AV delay was determined at rest, atrial pacing rate was increased at $10 \mathrm{bpm}$ increments from baseline heart rate of 60 or $70 \mathrm{bpm}$ to a maximum of $90 \mathrm{bpm}$. At each atrial pacing rate, mitral inflow PW Doppler was first evaluated at the AV delay found optimal at the previous paced atrial rate. Then the AV delay was decreased in decrements of $20 \mathrm{~ms}$ until best $\mathrm{E}$ and $\mathrm{A}$ wave separation was seen on mitral inflow without atrial truncation. If $\mathrm{E}$ and $\mathrm{A}$ separation did not occur despite decreasing AV delay, AV delay was increased in increments of 20 ms until E and A separation was noted. Atrial pacing rate ranged from $60-90$ beats per minute. In 13 patients LV ejection time was also evaluated at each paced atrial rate before and after optimal AV delay change. PW Doppler assessment was performed 5 beats of after change in pacemaker setting.

\section{Echocardiography}

We used transthoracic echocardiography using GE Vivid 7 or Vivid 9 ultrasound systems (Horten, Norway) equipped with a variable frequency $2.5-5 \mathrm{MHz}$ transducer with harmonics. Echocardiogram was performed in the left lateral decubitus position. AV delay was first optimized at resting heart rate partially adopting the recent guidelines from American Society of Echocardiography [12]. PW Doppler sample volume placed at the tip of the mitral leaflets for LV diastolic filling parameters. PW Doppler sample volume was placed $0.5-1 \mathrm{~cm}$ below the aortic valve at the LV outflow tract (LVOT) to obtain the LV ejection duration and aortic velocity time integral (VTI). Frame rate was kept above 100 fps by using single focus, narrow imaging sector, appropriate depth and frame rate. Parallel Doppler beam alignment to myocardial segments and color Doppler was used for all Doppler data acquisition. ECG was displayed on the ultrasound system and 3 cardiac cycles were used for each data acquisition. Raw data was stored digitally as DICOM cine loops and transferred for offline analysis to a customized dedicated workstation equipped with custom built software (Echo PAC PC Dimension version 6.0.1, GE Vingmed Ultrasound, Horten, Norway) via internet.

\section{Offline Measurements}

All routine chamber dimensions and LV ejection fraction at baseline were measured off line. Mitral inflow peak $\mathrm{E}$ and $\mathrm{A}$ velocities, $\mathrm{E}$ wave deceleration time and mitral inflow VTI were measured at baseline and at each paced heart rate. We also measured LVOT PW Doppler ejection time and VTI in 13 patients at fixed AV delay and optimal AV delay at increased atrial pacing rates. Two blinded independent investigators performed offline analysis of all echo data. Investigators performing offline analysis were blinded to online assessment of optimal AV delay settings.

\section{Functional Class Assessment}

NYHA class was evaluated at baseline and Quality of Life was assessed by Minnesota Living with Heart 
Failure Questionnaire (MHFQ) at baseline. NYHA class and MHFQ were re-evaluated by a questionnaire given to the patient in a self addressed envelope to be mailed in at 1 month post optimization. A hall walk as tolerated by the patient was performed on all patients after optimization to ensure no deterioration of exercise capacity from baseline.

\section{Statistical analysis}

All measurements were displayed as mean \pm SD. Measurements before and after optimization for AV delay for each heart rate as well as NHYA and functional class scores were analyzed by Paired student $\mathrm{t}$ - test. For comparison of different heart rates, we used analysis of variance (ANOVA). We used repeated measures ANOVA for optimal measured AV delay at more than two different heart rates. $\mathrm{P}<0.05$ was considered statistically significant.

\section{Results}

34 patients were included in our study. Baseline characteristics of the study population are shown in Table 1. The mean duration of CRT implant prior to optimization was $23 \pm 27$ months.

\section{Effect of Optimal AV delay Programming at Resting Paced Atrial Rate}

Change in diastolic filling and systolic ejection PW Doppler parameters and on peak pulmonary artery pressure from baseline AV delay to optimal AV delay at resting HR is shown in Table 2. Figure 1 is a study example of a patient showing mitral inflow, pulmonary vein inflow

Table 1 Baseline Characteristics of the Study Population

\begin{tabular}{ll}
\hline Age & $75 \pm 11$ years \\
\hline Gender & Male/Female: $24(72 \%) / 10(28 \%)$ \\
\hline NYHA & $2.6 \pm 0.7-$ I/II/III/IV: 3\%/34\%/47\%/ \\
& $16 \%$ \\
\hline CYHA & $2.6 \pm 0.7-$ I/II/III/IV: 3\%/34\%/47\%/ \\
\hline & $16 \%$ \\
\hline QRS Duration & $31 \%$ \\
\hline Left Ventricular Diastolic & $175.3 \pm 38.6 \mathrm{~ms}$ \\
\hline Diameter & $5.9 \pm 0.93 \mathrm{~cm}$ \\
\hline Left Ventricular Systolic Diameter & $4.9 \pm 1.1 \mathrm{~cm}$ \\
\hline Left Ventricular Ejection Fraction & $34.1 \pm 12.4 \%$ \\
\hline Left Atrial Diameter (Superior- & $6 \pm 1 \mathrm{~cm}$ \\
Inferior) & $4.7 \pm 0.8 \mathrm{~cm}$ \\
\hline Left Atrial Diameter (Antero- & \\
\hline Posterior) & $154.1 \pm 40.1$ (baseline) \\
\hline AV Delay &
\end{tabular}

Table 2 Effect of Biv Pacemaker Optimization on Echo Doppler Variables at Baseline Heart Rate

\begin{tabular}{llll}
\hline Echo Doppler Variables & Baseline & Optmial & P Value \\
\hline LV Diastolic Filling Time (ms) & $396 \pm 75$ & $420 \pm 63$ & 0.016 \\
\hline LVOT VTI (cm) & $17.5 \pm 4.8$ & $19.4 \pm 5.2$ & $<0.001$ \\
\hline LV ejection time (ms) & $287 \pm 40$ & $298 \pm 36$ & $<0.001$ \\
\hline Pulmonary artery pressure (mm Hg) & $52 \pm 7$ & $44 \pm 8$ & 0.001 \\
\hline $\begin{array}{l}\text { Values are Mean } \pm \text { SD LV: left ventricle.; LVOT: left ventricular outflow tract; } \\
\text { VTI: velocity time integral }\end{array}$
\end{tabular}

and LVOT PW Doppler measurement at baseline AV delay and at optimal AV delay at resting HR of $60 \mathrm{bpm}$.

\section{Increased Atrial Pacing}

Patients tolerated increasing atrial pacing rate without developing arrhythmia or hypotension. Mean duration of atrial pacing during which Doppler echo data for diastolic filling time at fixed and variable AV delays was collected was 2 minutes. In 13 patients in whom echo Doppler systolic ejection time before and after AV delay optimization was also obtained, mean duration of atrial pacing was 3 minutes.

\section{Changes in Optimal AV Delay With Increasing Heart Rate}

$81 \mathrm{AV}$ delays were evaluated at different atrial pacing rates. Data on optimal AV delay at each paced heart rate in the overall study population is shown in Table 3 . In 32 patients, optimal AV delay decreased as atrial paced rate increased. Optimal AV delay was $201 \mathrm{~ms}$ at $60 \mathrm{bpm}, 187 \mathrm{~ms}$ at $70 \mathrm{bpm}, 146 \mathrm{~ms}$ at $80 \mathrm{bpm}$ and 123 $\mathrm{ms}$ at $90 \mathrm{bpm}$ ( $\mathrm{p}=0.001$ by ANOVA for all) and is shown in Figure 2. Repeated measures ANOVA showed a statistically significant shortening of AV delay at three sets of heart rates $(60,70$ and $80 \mathrm{bpm}, \mathrm{P}<0.001)$. Optimal AV delay at baseline and increased paced atrial rate in each patient is shown in Figure 3.

\section{Effect of Optimal AV Delay on Diastolic Parameters}

Data on diastolic filling time, mitral inflow VTI, E wave deceleration time, $\mathrm{E}$ and $\mathrm{A}$ wave velocities, $\mathrm{E} / \mathrm{A}$ ratio, LVOT ejection time and LVOT VTI at various heart rates during fixed and optimal AV delays is shown in Table 4. Figures 4 and 5 show mitral inflow PW Doppler tracings with increased atrial pacing rate at fixed and optimal AV delay at a heart rate of $70 \mathrm{bpm}$ (Figure 4 ) and then $80 \mathrm{bpm}$ (Figure 5) in a study patient. Absolute and percent changes in PW Doppler mitral inflow and of LVOT at fixed and optimal AV delay at $81 \mathrm{AV}$ delays tested are shown in Table 5. Diastolic filling time was significantly longer at optimal AV delay with a mean difference at fixed vs. optimal AV delay of $40.3 \pm$ $25 \mathrm{~ms}, \mathrm{p}<0.001$. Decreasing optimal AV delay with increased heart rate was associated with an increase in 

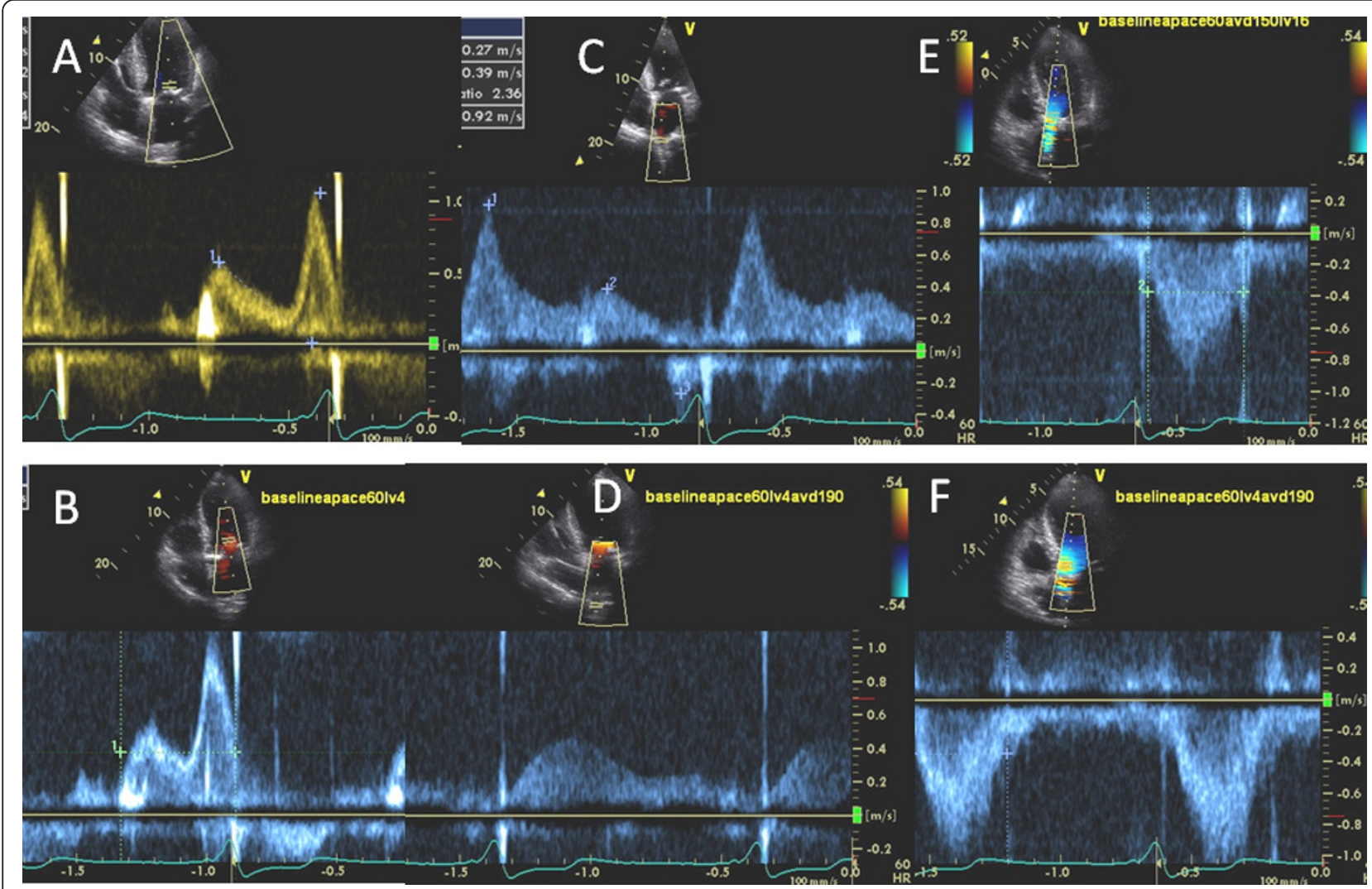

Figure 1 Effect of AV delay optimization on diastolic filling. Mitral inflow (A and B), pulmonary vein inflow (C and D), and LV outflow PW Doppler (E and F) at baseline (Apace 60 AV delay 150, LV 16 ms): A, C, and E) and optimal (A-paced 60 beats/min, AV delay 190 ms, W0 ms: B, $D$, and F) pacemaker settings. An increase in A wave duration occurred (B), and pulmonary vein pattern changed so that systolic fraction increased, S wave deceleration time increased (D) and increased pulmonary vein atrial reversal (C) was abolished indicating reduction in left atrial pressure. An improvement in percentage LV ejection time also occurred (F).

mitral inflow PW Doppler VTI. No significant change was seen in mitral inflow deceleration time at fixed vs. optimal AV delay. Mitral inflow A wave and E/A ratio showed statistically significant changes after optimization of AV delay at different heart rates (Table 4). LVOT systolic ejection time increased at optimal vs. fixed AV delay at increased heart rates, with a mean change of $11 \pm 15 \mathrm{~ms}(\mathrm{p}<0.02)$. A trend for an increased in LVOT VTI was noted before and after optimization (Tables 4 and 5).

\section{Final Pacemaker Settings}

Rate adaptive AV delay feature was turned $\mathrm{ON}$ in all patients and AV delay shortening was programmed according to AV delays found optimal at increased paced heart rate in each patient. In patients with St Jude device, AV delay settings were changed to the "most aggressive" AV delay shortening.

25 of the patients reported an improvement in their ability to walk immediately after optimization compared to before optimization and 5 patients were unable to tell

Table 3 Optimal AV Delay at Different Paced Atrial Rates in the Study Patients

\begin{tabular}{llllll}
\hline $\begin{array}{l}\text { Heart rate } \\
\text { (bpm) }\end{array}$ & $\mathbf{N}$ & Optimal AV delay(ms)* & 95\% Confidence Interval & $\begin{array}{l}\text { Minimum } \\
\text { AV delay(ms) }\end{array}$ & $\begin{array}{l}\text { Maximum } \\
\text { AV delay(ms) }\end{array}$ \\
\hline 60 & 9 & $201 \pm 48$ & $169.64-232.36$ & 190 & 230 \\
\hline 70 & 36 & $187 \pm 44$ & $172.63-201.37$ & 100 & 280 \\
\hline 80 & 25 & $146 \pm 42$ & $129.54-162.46$ & 80 & 200 \\
\hline 90 & 21 & $123 \pm 49$ & $102.04-143.96$ & 50 & 250 \\
\hline
\end{tabular}

Values are Mean \pm SD

*Optimal AV delay at different heart rates $(P$ value $=0.001$ ANOVA $)$ 


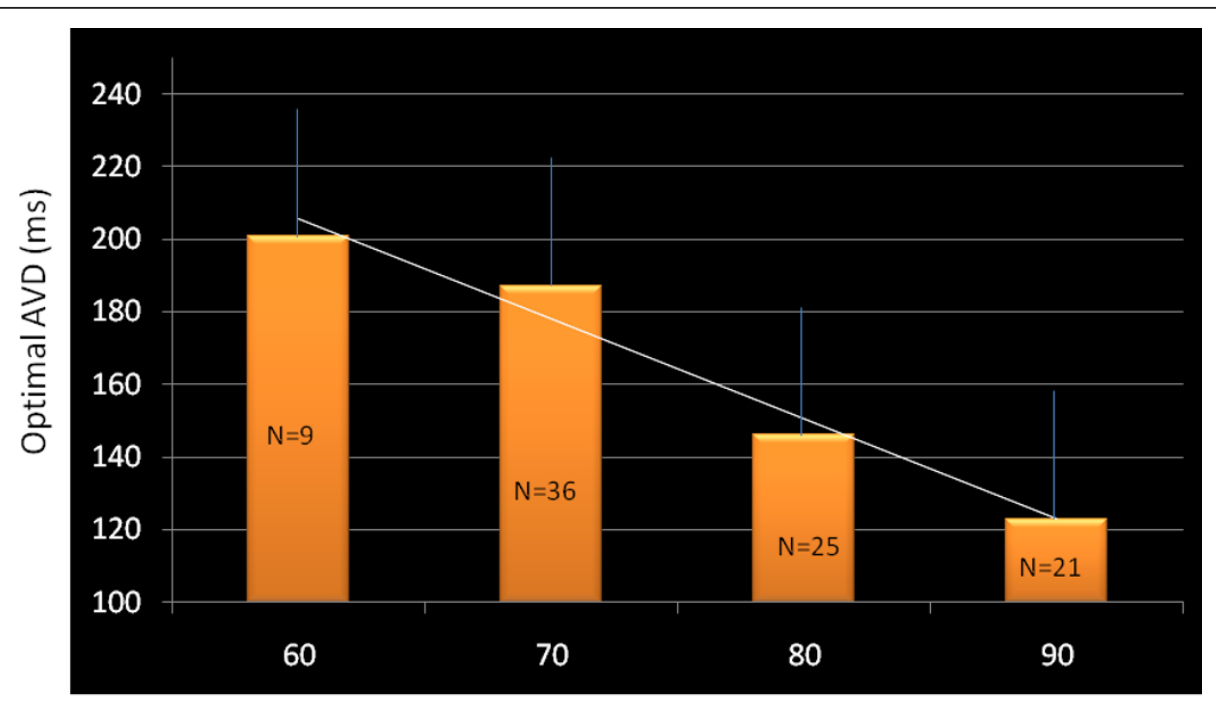

Paced Atrial Heart Rate (bpm)

Figure 2 Effect of increasing paced atrial rate on optimal AV delay in the study population.

the difference. No patient reported deterioration in exercise tolerance. NYHA improved from $2.5 \pm 0.8$ at baseline to $1.7 \pm 0.8(\mathrm{p}<0.01)$ at one month post optimization. MHFQA Failure Questionnaire was returned at the end of one month by 20 subjects. MHFQA improved from $49 \pm 30$ to $39 \pm 30(\mathrm{p}=0.2)$. When emotional and physical components of assessment were separated, a significant improvement was noted in the physical component of quality of life from $32 \pm 17$ to $25 \pm 12, \mathrm{p}<0.05$.

\section{NYHA Class by Device Manufacturer}

There were 14 Medtronic devices, 7 Boston Scientific devices and 10 St. Jude devices. Mean NYHA improvement for St Jude was 0.10 compared to 0.87 for all other brands $(\mathrm{p}=0.068)$. No differences were found for other brands.

\section{Discussion}

The salient findings of our study are that increased atrial pacing rate causes a marked shortening of diastolic filling time at a fixed AV delay and a shortening of AV delay at increased heart rate improves diastolic filling. This shortening of AV delay is associated with an improvement in LV ejection time and indirectly LV stroke volume. Optimization of AV delay at rest and programming of aggressive rate adaptive delay was associated with an improvement in NYHA functional class at 1 month follow up. The shortening of AV delay at increased heart rates allows adequate diastolic filling time by causing separation of early and late diastolic filling and in turn leads to an improvement in cardiac ejection as measured by LV systolic ejection time.
Aggressive shortening of AV delay at increased heart rates is further supported by the improvement in functional class that occurred in our patients at one month follow up.

Modern pacemaker devices allow rate-response as well as rate-adaptive AV delay shortening during exercise. Current pacemakers do not allow AV delay lengthening at increased heart rates. In our study the amount of AV delay shortening needed to optimize diastolic filling was more aggressive than current default automated pacemaker algorithms provide. This could be related to current rate-adaptive AV delay algorithms based on data derived from patients with conduction abnormalities who had otherwise preserved right ventricular and LV systolic function whereas patients with CRT have marked cardiac dysfunction.

We did not have a control group in whom rate adaptive AV delay shortening was not performed to differentiate effects of optimization at resting heart rates vs. optimization at resting heart rates and use of rate adaptive AV delay, however improvement in NYHA class and quality of life in our patients suggests that programming of aggressive rate adaptive delay shortening is not deleterious, as some studies suggest, and is likely to be beneficial. We selected patients who were atrial pacing in addition to Biv pacing at baseline since a constant heart rate provided by atrial pacing allowed patients to act as their own control in whom fixed versus shortened AV delay effects in a given cardiac cycle of constant length could be tested.

In humans with normal cardiac function, there is decreasing AV delay with increasing heart rate in a predictable manner $(4 \mathrm{~ms} / 10 \mathrm{bpm})$. Patients with dilated 


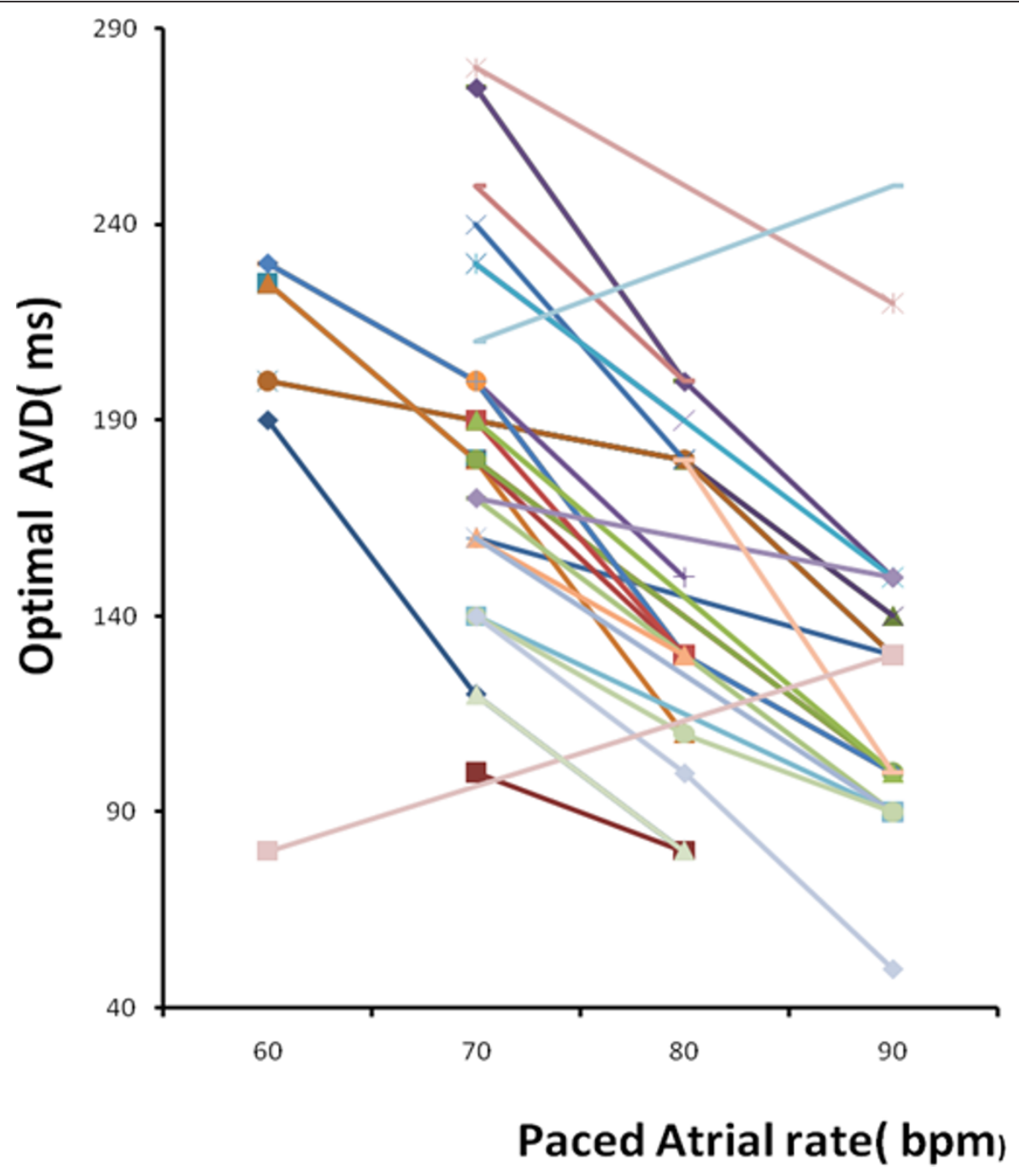

Figure 3 Optimal AV delay at increased paced atrial heart rates during biventricular pacing in each study patient

Table 4 Echo Doppler Measurements Before and After Optimization During Atrial Pacing Above Baseline Heart Rate

\begin{tabular}{llll}
\hline $\begin{array}{l}\text { Echo Doppler } \\
\text { Variables }\end{array}$ & $\begin{array}{l}\text { Before } \\
\text { Optimization }\end{array}$ & $\begin{array}{l}\text { After } \\
\text { Optimization }\end{array}$ & $\begin{array}{l}\mathbf{P} \\
\text { value }\end{array}$ \\
\hline $\begin{array}{l}\text { Diastolic filling time } \\
\text { (ms) }\end{array}$ & $279 \pm 60$ & $318 \pm 43$ & $<0.001$ \\
\hline Mitral inflow VTI (cm) & $14.9 \pm 5.7$ & $15.8 \pm 4.7$ & 0.04 \\
\hline E wave $(\mathbf{c m} / \mathbf{s})$ & $0.71 \pm 0.30$ & $0.72 \pm 0.25$ & 0.33 \\
\hline A wave $(\mathbf{c m} / \mathbf{s})$ & $0.70 \pm 0.29$ & $0.64 \pm 0.26$ & 0.01 \\
\hline E/A & $1.13 \pm 0.51$ & $1.27 \pm 0.65$ & $<0.001$ \\
\hline $\begin{array}{l}\text { Systolic ejection time } \\
\text { (ms) }\end{array}$ & $276 \pm 37$ & $285 \pm 38$ & 0.011 \\
\hline LVOT VTI (cm) & $14.7 \pm 3.8$ & $15.5 \pm 3$ & .21 \\
\hline
\end{tabular}

Values are Mean \pm SD. LVOT: left ventricular outflow tract; VTI: velocity time integral cardiomyopathy have prolongation of LV systole and an abnormal shortening of LV diastole at rest [13] that is accentuated during exercise [11]. In addition, abnormal shortening of LV diastolic time requires higher left atrial pressures to maintain LV filling during exercise resulting in pulmonary congestion and exercise intolerance $[10,12]$. Although previous studies showed the importance of periodically optimizing AV delay [14] there is insufficient data on changes in AV delay with pacing at various heart rates. These studies are summarized in Table 6. Scharf et al [8] attributed probable longer diastolic filling with prolonging of AV delay that caused an improvement in LVOT VTI. However physiologically, prolongation of AV delay should lead to approximation of $E$ and $A$ waves due to pushing back of atrial contraction towards early diastole when early diastolic filling (E wave on PW Doppler) occurs. Calculation of AV delay 


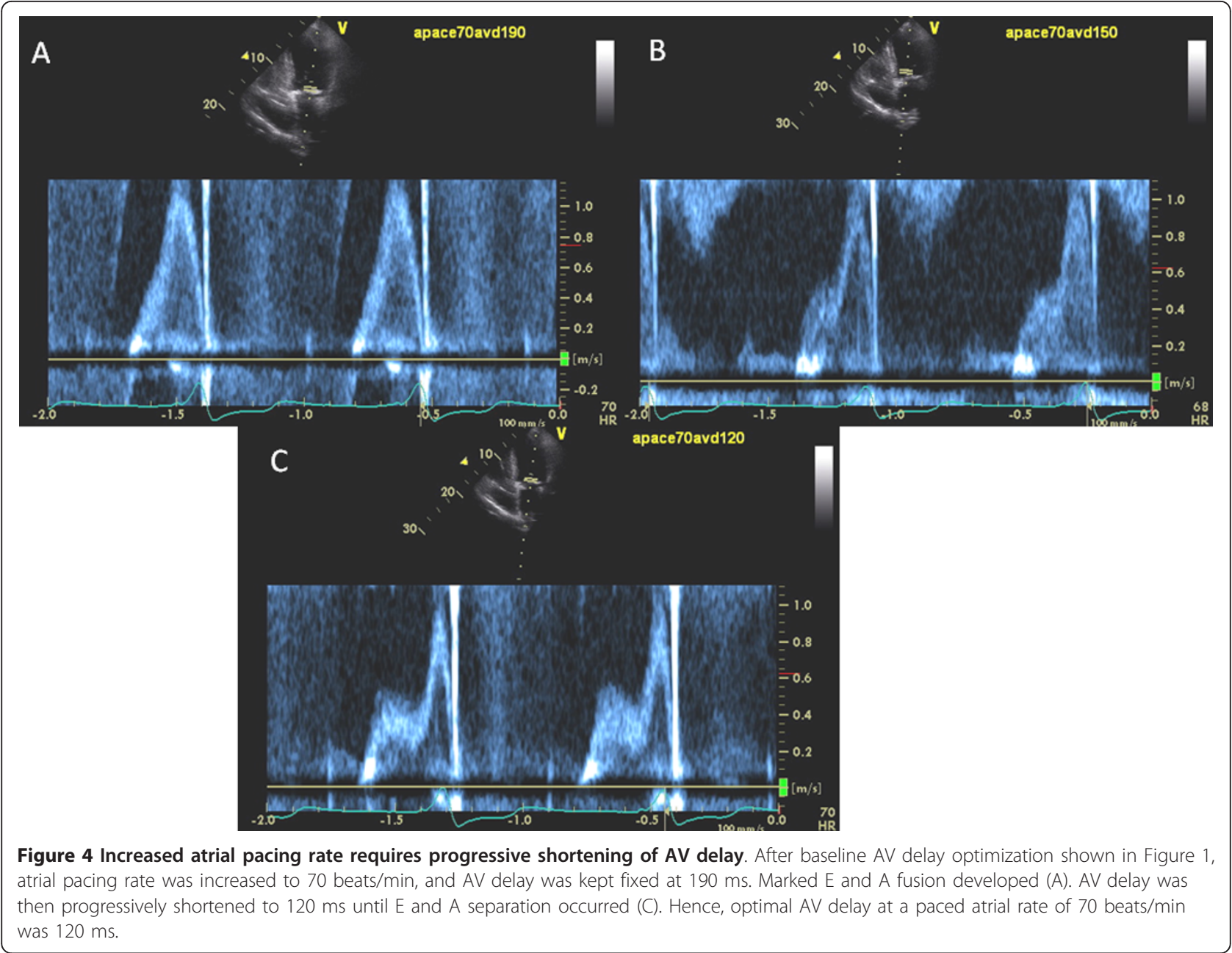

immediately after exercise with unstable heart rates may have confounded their results.

Recent study by Mokrani et al [15] found that variable changes in optimal AV delay were needed during exercise when using LVOT VTI and diastolic filling time in patients. Changing heart rates during Doppler assessment may have led to variable results. Study by Valzania et al found variation in VV delay from rest to exercise but no significant changes in AV delay using LVOT VTI to optimize AV delay during rest and exercise [16].

Contrary to findings of these earlier studies, several other studies found that shortening of AV delay is needed at increased heart rates. Melzer et al [9] found that optimal AV delay was shorter with increasing heart rate during DDD (atrial-paced Biv pacing) pacing and not during VDD (atrial-sensed Biv-pacing) pacing during exercise. All patients included in this study were responders by NYHA class and were enrolled 6 months post CRT. To calculate optimal AV delay, interatrial conduction time (time between atrial stimulus and left atrial deflection), left atrial electromechanical time (time between left atrial deflection and the end of the A wave on mitral diastolic filling) and LV latency period (time between ventricular pacing stimulation and end of truncated A wave on programming the pacemaker at a nonphysiologic short AV delay) were measured. During exercise, interatrial conduction time and LV latency period did not change significantly but left atrial electromechanical action decreased significantly with patients in the DDD mode. Thus stable electrical conduction time but variable diastolic filling time at different heart rates was found in this study.

Whinnett et al [17] determined optimal AV delay at rest and during exercise using non invasive finger arterial pressure measurements. Their results showed shortening of AV delay at increased heart rate in 11 patients while 8 patients needed lengthening of AV delay. Measurements of optimal AV delay at three different phases as described above at rest could predict the exercise optimal AV delay with good agreement $(r=0.85)$, however only using optimal AV delay during atrial sensing at rest was less reliable in predicting optimal AV delay 


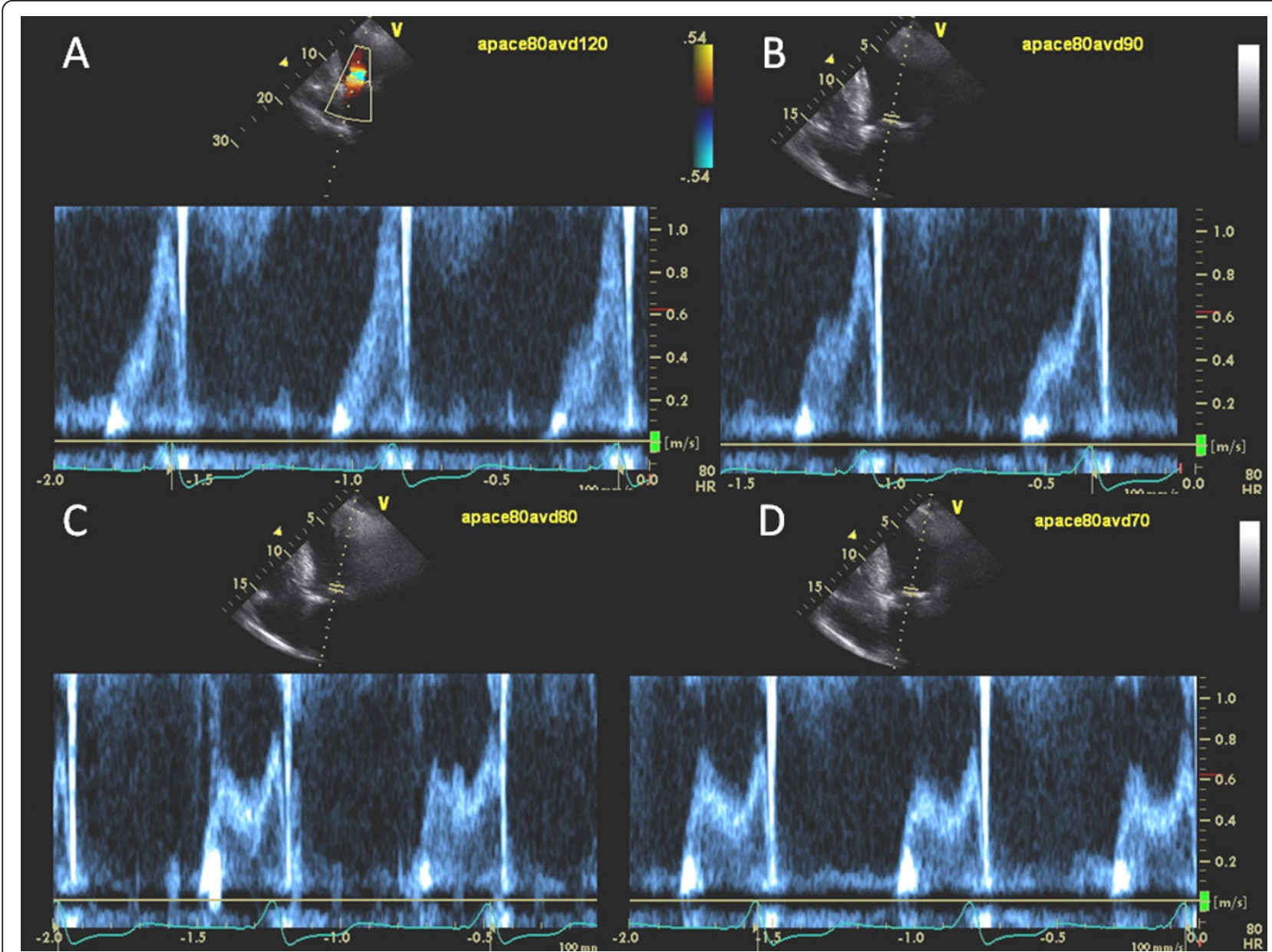

Figure 5 Increased Atrial Pacing Rate Requires Progressive Shortening of AV delay. After optimization AV delay at atrial pacing rate of 70 bpm in the same patient as shown in Figure 4, paced atrial rate was then increased to 80 beats/min at the AV delay of 120 ms. Marked E and A fusion developed again (A). Progressive shortening of AV delay to $90 \mathrm{~ms}$ (B), and then $80 \mathrm{~ms}$ (C) caused mitral inflow E and A separation. Further shortening of AV delay to $70 \mathrm{~ms}$ (D) led to shortening of mitral inflow A-wave and premature closure of mitral valve. Hence, optimal AV delay at a paced atrial rate of $80 \mathrm{bpm}$ was $80 \mathrm{~ms}$.

at increased heart rates. The study showed predictive value of atrial pacing at rest for optimal exercise AV delay.

Tse et al [18] evaluated changes in AV delay in CRT patients during exercise treadmill test using mitral inflow PW Doppler parameters. AV delay optimization

Table 5 Effect of Fixed versus Optimal AV Delay on Echo Doppler Parameters at Increased Atrial Pacing Rates

\begin{tabular}{llll}
\hline Echo Doppler Variable & $\begin{array}{l}\boldsymbol{\Delta} \text { Fixed vs. Opt AV } \\
\text { Delay }\end{array}$ & $\begin{array}{l}\% \\
\boldsymbol{\Delta}\end{array}$ & $\mathbf{P}$ \\
\hline Diastolic Filling Time (ms) & $40.2 \pm 25$ & 14 & $<0.001$ \\
\hline Mitral inflow VTI (cm) & $0.92 \pm 2$ & 5 & 0.04 \\
\hline $\begin{array}{l}\text { Systolic Ejection Time (ms, } \mathbf{n} \\
=\mathbf{1 3})\end{array}$ & $11 \pm 15$ & 4 & 0.011 \\
\hline LVOT VTI $(\mathbf{c m}, \mathbf{n}=\mathbf{1 3})$ & $0.56 \pm 1.6$ & & \\
\hline
\end{tabular}

Values are Mean \pm SD or percent change by echocardiography provided the longest mitral filling time without truncation of A wave. 55\% of patients had severe chronotropic incompetence and achieved $<70 \%$ age-predicted heart rate during exercise. These patients showed increased peak exercise heart rate, exercise time and peak oxygen consumption by appropriate use of rate-adaptive pacing.

Our study differs from these earlier studies in that our study population is older, on average by 10 years, had a higher NYHA class, most were unable to perform more than mild exercise and all were DDD pacing indicating conduction system disease. In addition ours is the only study which was not only observational but rate adaptive AV delay was programmed according to findings of optimal AV delay and increased atrial pacing rate. Another differentiating feature of our study that 32 of our 34 patients required a decrease in AV delay with 
Table 6 Prior Studies That Evaluated the Effect of Increased Heart Rate on Optimal Atrioventricular Delay in Patients with CRT

\begin{tabular}{|c|c|c|c|c|c|c|}
\hline Author & $\mathbf{N}$ & $\begin{array}{l}\text { Study } \\
\text { Population }\end{array}$ & Heart rate tested & How HR Increased & $\begin{array}{l}\text { Method to calculate } \\
\text { Opt AV Delay }\end{array}$ & $\begin{array}{l}\text { Optimal AV Delay at } \\
\text { Increased Heart Rate }\end{array}$ \\
\hline $\begin{array}{l}\text { Melzer et } \\
\text { al }\end{array}$ & 20 & $\begin{array}{l}\text { CRTresponder } \\
64 \pm 10 \text { yrs, } \\
\text { NYHA }<3 . \text { VDD } \\
\text { and DDD mode } \\
\text { used. EF } 23.2 \pm \\
7.6\end{array}$ & $\begin{array}{l}22.5 \pm 9.6 \text { bpm above } \\
\text { baseline Supine bicycle } \\
\text { ergometer beginning with } \\
25 \mathrm{~W} \text { and increasing the } \\
\text { workload by } 25 \mathrm{~W} \text { every } 2 \\
\text { min. }(71+9 \mathrm{~W}) \text {. }\end{array}$ & Supine bicycle exercise & $\begin{array}{l}\text { Combination of mitral } \\
\text { inflow PW Doppler, } \\
\text { trans-esophagel left } \\
\text { atrial electrograms and } \\
\text { surface ECG. }\end{array}$ & $\begin{array}{l}\text { No AV delay change } \\
\text { needed in VDD mode. With } \\
\text { DDD mode, optimal AV } \\
\text { delay was shortened by } 2.6 \\
\text { ms/10 bpm }\end{array}$ \\
\hline $\begin{array}{l}\text { Scharf et } \\
\text { al }\end{array}$ & 36 & $\begin{array}{l}\text { Biv-ICD, } 62 \pm 8 \\
\text { yrs, EF } 17 \pm 5\end{array}$ & $\begin{array}{l}\text { Pacing heart rate increased } \\
\text { to } 110-120 \mathrm{bpm} \text { and with } \\
\text { exercise increase in intrinsic } \\
\text { heart rate at least } 20 \mathrm{bpm} \\
\text { above baseline. Optimal AV } \\
\text { Delay determined post } \\
\text { exercise }\end{array}$ & $\begin{array}{l}\text { DDD pacing or treadmill } \\
\text { exercise In } 22 \text { patients with } \\
\text { DDD HR increased to 110- } \\
120 \text { bpm. In } 14 \text { patients } \\
\text { with exercise HR increased } \\
\text { at least } 20 \text { bpm above } \\
\text { baseline }\end{array}$ & LVOT VTI post exercise & $\begin{array}{l}\text { Prolongation of AV delay } \\
\text { found optimal at increased } \\
\text { HRs. An increase in LVOT } \\
\text { VTI of } 0.047 \mathrm{~cm} / \mathrm{s} \text { per } 20 \mathrm{~ms} \\
\text { prolongation of AV delay } \\
\text { per } 10 \mathrm{bpm} \text { increase in } \\
\text { heart rate for DDD pacing } \\
\text { and } 0.146 \mathrm{~cm} / \mathrm{s} \text { increase in } \\
V T I \text { per } 20 \mathrm{~ms} \text { prolongation } \\
\text { of AV delay per } 10 \text { bpm } \\
\text { increase in heart rate during } \\
\text { exercise. Beneficial effect of } \\
\text { AV delay prolonging was } \\
\text { observed until heart rate } \\
110 \text { bpm. }\end{array}$ \\
\hline $\begin{array}{l}\text { Grimm R } \\
\text { et al }\end{array}$ & 15 & $\begin{array}{l}\text { CRT patients } \\
\text { without atrial } \\
\text { pacing who } \\
\text { were able to } \\
\text { exercise, } 57 \pm \\
16 \text { yrs, EF } 37 \pm \\
15\end{array}$ & $\begin{array}{l}\text { Atrial-sensed Biv pacing, HR } \\
20-40 \text { bpm above baseline }\end{array}$ & Supine bicycle exercise & $\begin{array}{l}\text { Maximum LV filling } \\
\text { time. The duration of } \\
\text { LV filling, stroke } \\
\text { volume, and a clinical } \\
\text { assessment of LV } \\
\text { function were studied. }\end{array}$ & $\begin{array}{l}\text { AV delay shortening } \\
\text { needed at increased HR for } \\
\text { all patients using three } \\
\text { independent criteria. } \\
\text { Consistent trends were } \\
\text { observed between all three } \\
\text { parameters for } 12 \text { out of } \\
\text { the } 15 \text { patients. }\end{array}$ \\
\hline $\begin{array}{l}\text { Mokrani B } \\
\text { et al }\end{array}$ & 50 & $\begin{array}{l}\text { CRT patients } \\
\text { who were able } \\
\text { to exercise, } 69 \pm \\
7 \text { yrs, EF } 25 \pm 7\end{array}$ & $\begin{array}{l}\text { Atrial-sensed Biv pacing, } \\
60 \% \text { of the maximal } \\
\text { predicted. HR, with the } \\
\text { sensed AV delay set at } 40 \text {, } \\
70,100,120,150 \text {, and } 200 \\
\text { ms. Only } 1 \text { maximum HR } \\
\text { tested. }\end{array}$ & Supine bicycle exercise & $\begin{array}{l}\text { LVOT VTI, LV filling } \\
\text { time }\end{array}$ & $\begin{array}{l}\text { Optimal AV delay based on } \\
\text { LVOT-VTI was shorter during } \\
\text { exercise than at rest in } 37 \% \text {, } \\
\text { unchanged in } 37 \% \text {, and } \\
\text { longer in } 26 \% \text { of patients. } \\
\text { The optimal AV delay based } \\
\text { on mitral inflow filling time } \\
\text { was shorter during exercise } \\
\text { than at rest in } 27 \% \text {, } \\
\text { unchanged in } 23 \% \text {, and } \\
\text { longer in } 50 \% \text { of patients. } \\
\text { Opt-imization of AV delay } \\
\text { during exercise inc-reased } \\
\text { LV filling time and LVOT-VTI } \\
\text { (P < . .05) }\end{array}$ \\
\hline $\begin{array}{l}\text { Valzania } \\
C \text { et al }\end{array}$ & 24 & $\begin{array}{l}\text { CRT patients } \\
\text { able to exercise, } \\
63 \pm 9 \text { yrs, EF } \\
36 \pm 9\end{array}$ & $\begin{array}{l}\text { Atrial-sensed Biv pacing, 20- } \\
\text { beat increase in HR above } \\
\text { baseline. Only } 1 \text { maximum } \\
\text { HR tested. }\end{array}$ & Supine bicycle exercise & $\begin{array}{l}\text { LVOT VTI by PW } \\
\text { Doppler and } \\
\text { automated intra- } \\
\text { cardiac electrogram } \\
\text { (IEGM)to optimize AV } \\
\text { delay and W delay }\end{array}$ & $\begin{array}{l}\text { Optimal W delay varied } \\
\text { considerably from rest to } \\
\text { exercise, while AV delay did } \\
\text { not change. A substantial } \\
\text { agreement in deriving } \\
\text { optimized AV delays was } \\
\text { observed between the } \\
\text { echocardiogram and the } \\
\text { IEGM method, both at rest } \\
\text { and during exercise. }\end{array}$ \\
\hline
\end{tabular}


Table 6 Prior Studies That Evaluated the Effect of Increased Heart Rate on Optimal Atrioventricular Delay in Patients with CRT (Continued)

\begin{tabular}{|c|c|c|c|c|c|c|}
\hline $\begin{array}{l}\text { Whinnett } \\
\text { Zl et al }\end{array}$ & 20 & $\begin{array}{l}\text { CRT patients } \\
\text { who were able } \\
\text { to exercise, } 68 \\
\text { yrs(46-82 yrs) }\end{array}$ & $\begin{array}{l}\text { Atrial-sensed Biv pacing, HR } \\
\text { of } 100 \text { bpm with exercise. } \\
\text { Pacing at rest at } 5 \text { bpm } \\
\text { above resting rate and at } \\
100 \text { bpm. Sensed-paced } \\
\text { difference, calculated as an } \\
\text { "expected" value for the } \\
\text { exercise optimum. }\end{array}$ & Treadmill exercise & $\begin{array}{l}\text { Noninvasive finger } \\
\text { arterial pressure } \\
\text { measurements using a } \\
\text { Finometer }\end{array}$ & $\begin{array}{l}\text { Hemodynamic optimization } \\
\text { of AV delay under three } \\
\text { different conditions before } \\
\text { exercise. The resting three- } \\
\text { phase model correlated } \\
\text { well with the actual } \\
\text { exercise optimal AV delay ( } \mathrm{r} \\
=0.85 \text {, mean difference } \pm \\
\text { standard [SD] = } 3.7 \pm 17 \\
\text { ms). In } 11 \text { patients, the } \\
\text { optimal AV delay was } \\
\text { shorter during exercise than } \\
\text { at rest, in eight patients it } \\
\text { was longer and in } 1 \text { patient, } \\
\text { unchanged. }\end{array}$ \\
\hline $\begin{array}{l}\text { Tse } \\
\text { Hung-Fat } \\
\text { et al }\end{array}$ & 20 & $\begin{array}{l}\text { CRT patients } \\
\text { who were able } \\
\text { to exercise, } 65 \pm \\
4 \text { yrs, EF } 27 \pm 3\end{array}$ & $\begin{array}{l}\text { AV delay adaptive algorithm, } \\
\text { maximum programmed } \\
\text { equal to the optimal resting } \\
\text { AV delay during atrial } \\
\text { pacing and the minimum } \\
\text { AV delay to the optimal } \\
\text { resting AV delay during } \\
\text { atrial pacing-50 bpm in 10- } \\
\text { ms decrements. }\end{array}$ & $\begin{array}{l}\text { Cardiopulmonary treadmill } \\
\text { exercise }\end{array}$ & $\begin{array}{l}\text { Longest LV filling time } \\
\text { without truncation of } \\
\text { the A wave from mitral } \\
\text { inflow PW Doppler }\end{array}$ & $\begin{array}{l}\text { In heart failure patients with } \\
\text { severe chronotropic } \\
\text { incompetence as defined } \\
\text { by failure to achieve }<70 \% \\
\text { target HR, appropriate use } \\
\text { of rate-adaptive pacing with } \\
\text { CRT provides incremental } \\
\text { benefit on exercise capacity } \\
\text { during exercise. }\end{array}$ \\
\hline
\end{tabular}

increasing heart rate and the amount of AV shortening was more aggressive than found by previous studies. We used atrial pacing at incremental heart rates in the physiologic range to mimic heart rates expected to be achieved in these patients during physiologic exercise. Our study also differs from above studies that we used mitral inflow and LVOT Doppler as well as pulmonary vein Doppler echocardiography to determine optimal AV delay at resting heart rates. In addition we showed in a subset of our study patient's improved systolic ejection time at optimal shortened versus fixed AV delays at increased heart rates. Above all we showed improvement in functional class as a result of pacemaker changes including use of dynamic rate adaptive AV delay shortening as determined by our pacing protocol.

The differences in NYHA class improvement show a trend to lower improvement in patients with St Jude device. This is likely due to a different AV delay shortening algorithm in St Jude devices that does not allow AV delay shortening until a heart rate of $90 \mathrm{bpm}$ and at that heart rate is programmable at 1-, 2-, or 3-ms shortening per 1 beat/min in rate (low, normal, high) vs. linear response between shortest heart rate and maximum heart rate for other devices. Given no other significant differences between manufacturer algorithms, this suggests that rate adaptive AV delay shortening is an important element in pacemaker programming.

Our finding suggest that individualized pacemaker optimization should be performed at rest and at increased heart rates and more aggressive shortening of the AV delay should be used as default pacemaker setting in most devices in patients with CRT who are in the atrial pacing Biv pacing mode (DDD pacing).

\section{Limitations}

Atrial pacing that may be less physiologic than intrinsic increase in atrial rate during exercise hence our findings may not apply to patients with predominant atrial sensing. Our use of dynamic AV delay shortening as determined by atrial pacing was limited by device algorithms by different manufacturers. We did not perform invasive study to assess stroke volume changes with various AV delay at different heart rates.

We evaluated functional class by NYHA and quality of life questionnaire and did not perform follow up echocardiographic assessment. However we do not anticipate a significant change in LVEF over time given prolonged time period since pacemaker implant. While improvement in functional class may have been subjective, it likely was a result of pacemaker optimization since no changes occurred in medications or medical or cardiac condition in our patients. Finally our study is not randomized that would allow true impact of rate adaptive AV delay change. Such a study should be performed.

\section{Conclusion}

Our data suggests that an individualized pacemaker programming should be performed. In most patients with CRT an increase in heart rate causes a compromise in diastolic filling which can be improved with a significant shortening of AV delay at increased pacing rates. Aggressive AV delay shortening as determined by acute 
atrial pacing protocol was associated with a significant improvement in functional class post CRT.

\author{
Author details \\ ${ }^{1}$ Echocardiographic Laboratories, Department of Medicine, Keck School of \\ Medicine, University of Southern California, Los Angeles, California, 90033 \\ USA. ${ }^{2}$ Department of Preventive Medicine, Keck School of Medicine, \\ University of Southern California, Los Angeles, California, 90033 USA.
}

\section{Authors' contributions}

RR participated in measuring echo data and writing the manuscript. SQ and NT collected the information, followed patient and carried out entering data. AO performed statistical analysis. TZN conceived of the study, designed and coordinated each step and revised the final version of manuscript prior to submission. All authors read and approve the final manuscript.

\section{Competing interests}

The authors declare that they have no competing interests.

Received: 28 December 2011 Accepted: 24 January 2012

Published: 24 January 2012

\section{References}

1. Auricchio A, Stellbrink C, Sack S, Block M, Vogt J, Bakker P, Huth C, Schöndube F, Wolfhard U, Böcker D, Krahnefeld O, Kirkels H, Pacing Therapies in Congestive Heart Failure (PATH-CHF) Study Group: Long-term clinical effect of hemodynamically optimized cardiac resynchronization therapy in patients with heart failure and ventricular conduction delay. $J$ Am Coll Cardiol 2002, 39:2026-33.

2. Valzania C, Gadler F, Eriksson MJ, Olsson A, Boriani G, Braunschweig F: Electromechanical effects of cardiac resynchronization therapy during rest and stress in patients with heart failure. Eur J Heart Fail 2007, 9:644-50.

3. Sawhney NS, Waggoner AD, Garhwal S, Chawla MK, Osborn J, Faddis MN: Randomized prospective trial of atrioventricular delay programming for cardiac resynchronization therapy. Heart rhythm 2004, 1:562-67.

4. Naqvi TZ, Rafique AM: Echocardiography-guided pacemaker optimization and radial artery tonometry. J Card Fail 2008, 14:583-9.

5. Taha N, Zhang J, Ranjan R, Daneshvar S, Castillo E, Guillen E, Montoya MC, Velasquez G, Naqvi TZ: Biventricular pacemaker optimization guided by comprehensive echocardiography-preliminary observations regarding the effects on systolic and diastolic ventricular function and third heart sound. J Am Soc Echocardiogr 2010, 23:857-66.

6. Taha N, Zhang J, Rafie R, Ranjan R, Qamruddin S, Naqvi TZ: Pre-ejection period by radial artery tonometry supplements echo Doppler findings during biventricular pacemaker optimization. Cardiovasc Ultrasound 2011, 28:9-20

7. Valzania C, Biffi M, Martignani C, Diemberger I, Bertini M, Ziacchi M, Bacchi L, Rocchi G, Rapezzi C, Branzi A, Boriani G: Cardiac resynchronization therapy: variations in echo-guided optimized atrioventricular and interventricular delays during follow-up. Echocardiography 2007, 24:933-9.

8. Scharf C, Li P, Muntwyler JR, Chugh A, Oral H, Pelosi F, Morady F, Armstrong WF: Rate-Dependent AV Delay Optimization in Cardiac Resynchronization Therapy. Pacing Clin Electrophysiol 2005, 28:279-84.

9. Melzer C, Bondke H, Thomas K, Nienaber CA, Baumann G, Ismer B: Should we use the rate-adaptive AV delay in cardiac resynchronization therapypacing? Europace 2008, 10:53-8.

10. Grimm RA, Sun JP, Agler D, Fitzgerald B, Wilkoff B, Hilpisch K, Perlic G, Chinchoy E: Shorter AV delays provide improved echocardiographic hemodynamics during exercise in patients receiving cardiac resynchronization therapy. Pacing Clin Electrophysiol 2009, 32:457-65.

11. Plehn G, Vormbrock J, Perings C, Machnick S, Zuehlke C, Trappe HJ, Meissner A: Loss of diastolic time as a mechanism of exercise-induced diastolic dysfunction in dilated cardiomyopathy. Am Heart J 2008, 155:1013-9.

12. Gorcsan J, Abraham T, Agler DA, Bax JJ, Derumeaux G, Grimm RA, Martin R, Steinberg JS, Sutton MS, Yu CM, American Society of Echocardiography Dyssynchrony Writing Group: Echocardiography for cardiac resynchronization therapy: recommendations for performance and reporting-a report from the American Society of Echocardiography Dyssynchrony Writing Group endorsed by the Heart Rhythm Society. J Am Soc Echocardiogr 2008, 21:191-213.

13. Plehn G, Vormbrock J, Zühlke C, Christ M, Perings C, Perings S, Trappe HJ, Meissner A: Disproportionate shortening of left ventricular diastolic duration in patients with dilated cardiomyopathy. Med Klin (Munich) 2007, 102:707-13.

14. O'Donnell D, Nadurata V, Hamer A, Kertes P, Mohamed U: Long-term variations in optimal programming of cardiac resynchronization therapy devices. Pacing Clin Electrophysiol 2005, 28:S24-S26.

15. Mokrani B, Lafitte S, Deplagne A, Ploux S, Laborderie J, Reant P, Dos Santos P, Roudaut R, Jais P, Haissaguerre M, Clementy J, Bordachar P: Echocardiographic study of the optimal atrioventricular delay at rest and during exercise in recipients of cardiac resynchronization therapy systems. Heart Rhythm 2009, 6:972-7.

16. Valzania C, Eriksson MJ, Boriani G, Gadler F: Cardiac resynchronization therapy during rest and exercise: comparison of two optimization methods. Europace 2008, 10:1161-9.

17. Whinnett ZI, Briscoe C, Davies JE, Willson K, Manisty CH, Davies DW, Peters NS, Kanagaratnam P, Hughes AD, Mayet J, Francis DP: The atrioventricular delay of cardiac resynchronization can be optimized hemodynamically during exercise and predicted from resting measurements. Heart Rhythm 2008, 5:378-86.

18. Tse HF, Siu CW, Lee KL, Fan K, Chan HW, Tang MO, Tsang V, Lee SW, Lau CP: The incremental benefit of rate-adaptive pacing on exercise performance during cardiac resynchronization therapy. J Am Coll Cardiol 2005, 46:2292-7.

doi:10.1186/1476-7120-10-2

Cite this article as: Rafie et al: Shortening of atrioventricular delay at increased atrial paced heart rates improves diastolic filling and functional class in patients with biventricular pacing. Cardiovascular Ultrasound 2012 10:2.

\section{Submit your next manuscript to BioMed Central and take full advantage of:}

- Convenient online submission

- Thorough peer review

- No space constraints or color figure charges

- Immediate publication on acceptance

- Inclusion in PubMed, CAS, Scopus and Google Scholar

- Research which is freely available for redistribution

Submit your manuscript at www.biomedcentral.com/submit
C Biomed Central 